\title{
Myxoma of the Ovary: in Regard to Bedir et al. (Balkan Med J 2018;35:120-121)
}

\author{
Nicolas Sterkers 1 , Francis Salvat², Philippe Sappa ${ }^{3}$, Olivier Donnez ${ }^{1}$ \\ ${ }^{1}$ Department of Cancerology and Gynecology Surgery, Urbain V Clinic, Avignon, France \\ ${ }^{2}$ Radiology Center, Scanner Clinique Fontvert Urbain V, Sorgues, France \\ ${ }^{3}$ Pathology Center, Histosud, Chemin De Faufinette, Valreas, France
}

To the Editor,

In the January 2018 issue of Balkan Medical Journal, Bedir et al. (1) reported a new case of an ovarian myxoma, an exceedingly rare ovarian tumor. Although ovarian myxoma is a benign tumor that occurs predominantly in young women in whom fertility preservation is a major concern, the authors suggest that total excision of the tumor together with the adnexal structures is advisable because of the difficulty of total excision of viscous material that may cause recurrences. Here we describe a case wherein safe and efficient ovarian-sparing surgery was offered to a young woman with an ovarian myxoma, and we suggest this approach as a valuable option to treat this benign tumor.

A 22-year-old woman, 0 gravida, with an abdominal mass was referred to our department. Her medical history was characterized by achondroplasia with hydrocephalus that was cured by ventriculoperitoneal shunting in early childhood. Gynecological history was uneventful. Ultrasound and subsequent computed tomography of the abdomen after contrast administration revealed a well-defined cystic lesion $(8 / 10.5 / 11 \mathrm{~cm})$ with a thin capsular wall in the right iliac fossa. The tumor was adjacent to the ventriculoperitoneal-shunt catheter but inextricably linked to the right ovary, which argued against the diagnosis of a pseudocyst related to ventriculoperitoneal shunting complication. The CA-125 biomarker showed a normal value $(28.5 \mathrm{IU} / \mathrm{mL})$. A multidisciplinary consultation predicted the tumor to be benign, and a laparoscopic fertility-sparing surgery was scheduled. An exploratory laparoscopy revealed that the tumor was a well-circumscribed cystic mass arising from the right ovary, free of adjacent structures, with an external gray, translucent, and smooth surface. Given the normally looking abdomen, the absence of abnormal nodes, and the need for optimal fertility preservation, complete cystectomy preserving both ovaries was selected as the therapeutic approach. The cyst section revealed cystic spaces filled by gelatinous material. After aspiration of the cyst, the incision was enlarged. Blunt and sharp dissection helped to find a cleavage plane between the cyst wall and the ovarian cortex. The entire tumor was removed using an endobag to avoid tumor spillage. The peritoneal cavity was washed with saline, and the fluid was aspirated at the end of the procedure. Pathological examination revealed abundant myxoid stroma with positive staining with alcian blue, limited fibrotic spaces, and interspaced spindle-shaped tumor cells without atypia, of which approximately half stained with alpha-smooth muscle actin. Staining for S100 protein, keratin (AE 1/3), and inhibin was negative. Ki67 expression was low (3-4\%). The diagnosis of ovarian myxoma was made and confirmed by the French National Cancer Institute committee. No recurrence was detected even 6 years after the operation. The patient provided a written informed consent for publication.

Data on ovarian myxoma management are scarce and mostly extrapolated from isolated case reports or small histopathological series. This rare tumor was first mentioned in 1960 in a 14-yearold case. In 1991, Eichorn reported five personally observed cases and reviewed three additional previously described cases (2). We found seven additional isolated cases with acceptable, although limited, clinical documentation. Thus, a total of 15 cases have been reviewed till date. Ovarian myxoma frequently occurs in women at the reproductive age (9/16 cases, including ours, were aged $\leq 40$ years), with a peak of incidence lying between ages 12 and 25 years $(n=9 / 16,56 \%)$. The available clinical characteristics, management, and the outcome of the nine cases aged $\leq 40$ years (15 ) are summarized in the Table 1. Ovarian masses in young women require a thoughtful consideration to the preservation of the ovary if the preoperative suspicion of malignancy is low and there is no evidence of malignancy intraoperatively (6-10). Nevertheless, as shown in the table, ovarian myxoma has traditionally been removed through unilateral oophorectomy even in women at the reproductive age $(n=8 / 8)$. Furthermore, laparoscopy that has been established as an adequate alternative to laparotomy for the treatment of benign ovarian tumors (11) reduces postoperative adhesion formation that may compromise fertility. Safe and efficient treatment of our case by laparoscopic ovarian-sparing surgery suggests that this approach is convenient for adolescent and young women in whom any effort should be made to preserve fertility. However, two primary considerations should still be taken into account. The tumor must
Address for Correspondence: Nicolas Sterkers, Department of Cancerology and Gynecology Surgery, Urbain V Clinic, Avignon, France

Phone: +33 (4) $90898400 \quad$ e-mail: n.sterkers@ica84.org ORCID ID: orcid.org/0000-0003-2232-5829

Received: 19 September 2018 Accepted: 28 September 2018 • DOI: 10.4274/balkanmedj.2018.1454

Available at www.balkanmedicaljournal.org

Cite this article as:

Sterkers N, Salvat F, Sappa P, Donnez O. Myxoma of the Ovary: in Regard to Bedir et al. (Balkan Med J 2018;35:120-121). Balkan Med J 2019;36:64-5

${ }^{\circ}$ Copyright 2019 by Trakya University Faculty of Medicine / The Balkan Medical Journal published by Galenos Publishing House. 
TABLE 1. Primary clinical characteristics of eight cases aged $\leq 40$ years reported in the literature and our case

\begin{tabular}{cccccccc}
\hline $\begin{array}{c}\text { Age } \\
\text { (years) }\end{array}$ & Clinical signs & $\begin{array}{c}\text { Diameter } \\
\text { (longestmeasure) }\end{array}$ & $\begin{array}{c}\text { Imaging data } \\
\text { available }\end{array}$ & Treatment & Surgery & Outcome & References \\
\hline 25 & Routine examination & $8 \mathrm{~cm}$ & No & RSO & Unknown & NER at 13 years & Eichhorn and Scully (2) \\
32 & Routine examination & $9 \mathrm{~cm}$ & US & RSO & Unknown & NER at 18 months & Eichhorn and Scully (2) \\
19 & Abdominal mass & $18 \mathrm{~cm}$ & No & RSO & Unknown & Unknown & Eichhorn and Scully (2) \\
16 & Abdominal pressure & $22 \mathrm{~cm}$ & US & LSO & Unknown & Unknown & Eichhorn and Scully (2) \\
13 & Abdominal pain & $15 \mathrm{~cm}$ & No & LSO & Opensurgery & NER at 31 years & Têtu and Bonenfant (3) \\
12 & Abdominal mass & $8 \mathrm{~cm}$ & US & LSO & Unknown & NER at 1 year & Pai et al. (4) \\
25 & Routine examination & $8 \mathrm{~cm}$ & No & LO & Unknown & Unknown & Kim et al. (5) \\
12 & Menstrual irregularities & $6 \mathrm{~cm}$ & US & RO & Unknown & Unknown & Bedir et al. (1) \\
22 & Abdominal pain & $11 \mathrm{~cm}$ & US, CT scan & cysectomy & Laparoscopy & NER at 6 years & Sterkers at al. (This report) \\
\hline
\end{tabular}

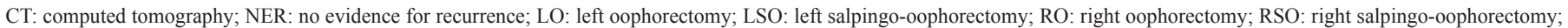
US: ultrasonography

be presumed to be at low risk based on careful preoperative and operative evaluation. When this rare tumor is postoperatively diagnosed by histopathological examination, the surgeon must be adequately trained in oncological procedures to avoid tumor spillage (12).

Acknowledgement: We thank the patient for participating in the study, the French National Cancer Institute committee for the expert advice, an the nurses and medical staff who took care of the patient.

Conflict of Interest: No conflict of interest was declared by the authors.

Financial Disclosure: No financial disclosure was declared by the authors.

\section{REFERENCES}

1. Bedir R, Yılmaz R, Calapoğlu AS. Myxoma of the Ovary. Balkan Med J 2018;35:120-1

2. Eichhorn JH, Scully RE. Ovarian myxoma: clinicopathologic and immunocytologic analysis of five cases and a review of the literature. Int J Gynecol Pathol 1991;10:15669.

3. Têtu B, Bonenfant JL. Ovarian myxoma. A study of two cases with long-term followup. Am J Clin Pathol 1991;95:340-6.
4. Pai S, Naresh KN, Desai PB, Borges AM. Ovarian myxoma in a premenarchal girl Gynecol Oncol 1994;55(3 Pt 1):453-5.

5. Kim MA, Kim JH, Ro JY, Ahn G, Park IA. Myxoma of the ovary with uncertain malignant potential - A case report. Korean J Pathol 2004;38:434-7.

6. Amies Oelschlager AM, Gow KW, Morse CB, Lara-Torre E. Management of Large Ovarian Neoplasms in Pediatric and Adolescent Females. J Pediatr Adolesc Gynecol 2016;29:88-94.

7. Gonzalez DO, Minneci PC, Deans KJ. Management of benign ovarian lesions in girls: a trend toward fewer oophorectomies. Curr Opin Obstet Gynecol 2017;29:289-94.

8. Oltmann SC, Garcia N, Barber R, Huang R, Hicks B, Fischer A. Can we preoperatively risk stratify ovarian masses for malignancy? J Pediatr Surg 2010;45:130-4.

9. Quint EH, Smith YR. Ovarian surgery in premenarchal girls. J Pediatr Adolesc Gynecol 1999;12:27-9.

10. Oue T, Uehara S, Sasaki T, Nose S, Saka R, Yamanaka H, et al. Treatment and ovarian preservation in children with ovarian tumors. J Pediatr Surg 2015;50:2116-8.

11. Medeiros LR, Rosa DD, Bozzetti MC, Fachel JM, Furness S, Garry R, et al Laparoscopy versus laparotomy for benign ovarian tumour. Cochrane Database Syst Rev 2009;15:CD004751

12. Minig L, Padilla-Iserte P, Zorrero C. The Relevance of Gynecologic Oncologists to Provide High-Quality of Care to Women with Gynecological Cancer. Front Oncol 2015;5:308. 